\title{
Online Model-Based Stator-Fault Detection and Identification in Induction Motors
}

\author{
Cristian H. De Angelo, Member, IEEE, Guillermo R. Bossio, Member, IEEE, Santiago J. Giaccone, \\ María Inés Valla, Senior Member, IEEE, Jorge A. Solsona, Senior Member, IEEE, and \\ Guillermo O. García, Senior Member, IEEE
}

\begin{abstract}
In this paper, a model-based strategy for statorinterturn short-circuit detection on induction motors is presented. The proposed strategy is based on the generation of a vector of specific residual using a state observer. The vectorial residual is generated from a decomposition of the current estimation error. This allows for a fast detection of incipient faults, independently of the phase in which the fault occurs. Since the observer includes an adaptive scheme for rotor-speed estimation, the proposed scheme can be implemented for online monitoring, by measuring only stator voltages and currents. It is shown that the proposed strategy presents very low sensitivity to load variations and power-supply perturbations. Experimental results are included to show the ability of the proposed strategy for detecting incipient faults, including a low number of short-circuited turns and low fault current.
\end{abstract}

Index Terms-Detection, identification, induction motors (IMs), model based, observer, short circuit, stator faults.

\section{INTRODUCTION}

$\mathbf{E}$ ARLY detection of incipient faults is one of the most important issues in preventive and predictive maintenance. In modern industries, the majority of the equipment is driven by three-phase induction motors (IMs). Thus, condition monitoring of such motors constitutes an essential concern in any industry.

Different monitoring techniques have been used for fault detection on IMs and other electric machines [1]. The most common ones include vibration analysis [2], [3], stray flux [4], and stator current-signature analysis [5].

Stator windings short circuit is one of the most common faults in electric machines [6]. The winding-insulation damage

Manuscript received February 29, 2008; revised December 18, 2008. First published January 19, 2009; current version published October 9, 2009. This work was supported in part by the Universidad Nacional de Río Cuarto, by the Universidad Nacional del Sur, by the Universidad Nacional de La Plata, by FONCyT-ANPCyT, by MinCyT Cba, and by the Consejo Nacional de Investigaciones Científicas y Técnicas (CONICET).

C. H. De Angelo, G. R. Bossio, S. J. Giaccone, and G. O. García are with Consejo Nacional de Investigaciones Científicas y Técnicas, Argentina, and also with the Grupo de Electrónica Aplicada, Facultad de Ingeniería, Universidad Nacional de Río Cuarto, Río Cuarto 5800, Argentina (e-mail: cdeangelo@ieee.org).

M. I. Valla is with Consejo Nacional de Investigaciones Científicas y Técnicas, Argentina, and also with the Laboratorio de Electrónica Industrial, Control e Instrumentación, Departamento de Electrotecnia, Facultad de Ingeniería, Universidad Nacional de La Plata, La Plata 1900, Argentina.

J. A. Solsona is with the Consejo Nacional de Investigaciones Científicas y Técnicas, Argentina, and also with the Instituto de Investigaciones en Ingeniería Eléctrica "Alfredo Desages," Departamento de Ingeniería Eléctrica y de Computadoras, Universidad Nacional del Sur, Bahía Blanca 8000, Argentina.

Digital Object Identifier 10.1109/TIE.2009.2012468 can be produced by excessive heating, transient overvoltages, winding movement, or contamination. Such a fault produces high currents and winding overheating, resulting in severe phase-to-phase, turn-to-turn, or turn-to-ground faults. All these may lead to an irreversible damage in the windings or in the stator core. For such reasons, rapid detection of incipient faults between turns during motor operation is very important.

There exist several proposals for stator-fault diagnosis in IMs [6], [7]. For online monitoring, the most interesting strategies are based on current and/or voltage measurement. Such strategies do not require direct access to the motor, since they can be measured from the motor switchboard. Among these techniques, motor current-signature analysis (MCSA) is the most widely used, due to its simplicity [8]. However, for precise detection and identification of the fault, a good frequency resolution and precise knowledge of the motor slip is required [5], [9], [10]. Moreover, this technique requires the motor operation at steady state. To overcome this limitation, waveletbased analysis has been suggested [11].

Other proposed strategies are based on negative-sequence current monitoring [12], [13] or the analysis of the current vector radius [14]. Such strategies are very sensitive to supplyvoltage unbalances; therefore, they can produce false alarms. Other techniques, which are based on the monitoring of the components of the sequence impedance matrix [15] or on the theory of multiple reference frames [16], allow decoupling the effect of supply-voltage perturbation. They are also robust to the motor load state. However, all these strategies, the same as MCSA techniques, are only applicable to machines working in steady state, i.e., at constant speed and load.

Modern techniques based on artificial intelligence have also been proposed for correct identification of the motor fault [17]. Artificial neural networks [18] and neuro-fuzzy techniques [19] are used to automatically diagnose stator faults from current and voltage measurement, mainly in online condition-monitoring systems. For online diagnosis, observer-based [20], [21] and parameter-estimation techniques [22] have also been recently presented.

Since an early fault detection is the main objective of statorfault detection schemes, a model-based strategy for online stator-fault detection is presented in this paper. This strategy, previously proposed in [21], uses a state observer to obtain a vector of specific residuals, which allows for a rapid detection of incipient stator faults. The use of a vectorial residual makes the fault detection independent of the phase in which the fault occurs. To obtain similar results, some previously 
proposed strategies need three state observers, one for each motor phase [20].

A weak point of model-based techniques is parameter dependence [20]. To overcome this problem, a method to extract the component produced by the fault from the estimation error is proposed. Unlike [16], the negative-sequence component of the estimation error is used in this paper. This component is obtained through projecting the current estimation error in an inverse-sequence reference frame. Since common parameter errors produced by temperature variation or other perturbations are usually symmetric, they are not reflected in this negativesequence component, making the proposed strategy very low sensitive to such perturbations. This method combined with the state observer allows the early detection of incipient stator faults even under varying load or speed. The error decomposition also allows the implementation of a speed-adaptation scheme, avoiding the use of a speed or position sensor, which is needed in some previously proposed model-based strategies [16], [22].

In this paper, the development of the strategy proposed in [21] is improved and extensively analyzed. A different severity factor is defined, and its ability to detect and diagnose very incipient faults is explored and tested by several experiments. In the following section, the IM model with stator faults is first presented. In Section III, the proposed strategy is developed, including a detailed analysis of the estimation error and its decomposition. Experimental results are presented in Section IV, while conclusions are drawn in Section V.

\section{IM Model With Stator Fault}

Model-based fault detection is basically founded on the comparison of the expected performance of the system against the actual one. The expected behavior is represented by the "normal-operation model" of the system. In order to design and evaluate the diagnosis strategies, a motor model that allows the inclusion of the fault effects is needed. Such a model is known as "faulty-operation model" [23].

Some models proposed in the literature are based on the winding-function theory [24]. This approach also allows a detailed analysis of the effects of interturn short circuits over the motor currents, but its complexity makes them unusable for online condition monitoring. A simpler model is proposed in [12], which includes interturn short circuits in the phase $a$ winding, as shown in Fig. 1. In [21], a new dynamic IM model was proposed. Different from the one presented in [12], this model allows consideration of interturn short circuits in any motor phase by means of a vectorial fault factor. This model is used here to develop and analyze the stator-fault detection and identification strategy.

By defining $\boldsymbol{\mu}_{q d}=\left[\begin{array}{ll}\mu_{q} & \mu_{d}\end{array}\right]^{\mathrm{T}}$ as the vector fault, its modulus represents the percentage of short-circuited windings, and the vector direction corresponds to the faulted phase. In most IMs, coils are insulated from one another in slots, as well as in the end-winding region. Therefore, the highest probability of occurrence of interturn short circuit is between turns in the same coil [24]. Then, if $\mu_{a}, \mu_{b}$, and $\mu_{c}$ are the percentages of short-

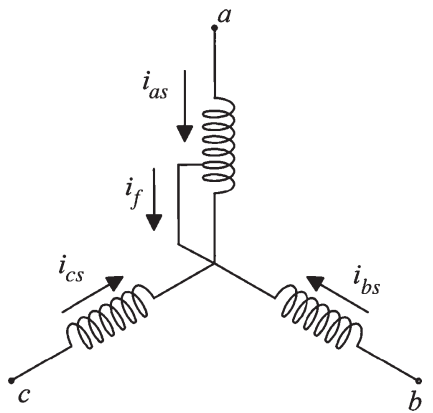

Fig. 1. Scheme of the stator phases with a short circuit between turns of phase $a$.

circuited windings in the phases $a, b$, and $c$, respectively, vector $\boldsymbol{\mu}_{q d}$ is given by

$$
\begin{aligned}
& \left.\boldsymbol{\mu}_{q d}\right|_{a}=\left[\begin{array}{ll}
1 & 0
\end{array}\right]^{\mathrm{T}} \mu_{a} \\
& \left.\boldsymbol{\mu}_{q d}\right|_{b}=\left[\begin{array}{ll}
-1 / 2 & \sqrt{3 / 2}
\end{array}\right]^{\mathrm{T}} \mu_{b} \\
& \left.\boldsymbol{\mu}_{q d}\right|_{c}=\left[\begin{array}{ll}
-1 / 2 & -\sqrt{3 / 2}
\end{array}\right]^{\mathrm{T}} \mu_{c} .
\end{aligned}
$$

The IM model with stator fault can be represented in a stationary reference frame $q d$, as follows:

$$
\begin{aligned}
& \left\{\begin{array}{l}
\frac{d \boldsymbol{\lambda}_{q d s}}{d t}=\mathbf{v}_{q d s}-R_{s} \mathbf{i}_{q d s}+\frac{2}{3} \boldsymbol{\mu}_{q d} R_{s} i_{f} \\
\frac{d \boldsymbol{\lambda}_{q d r}}{d t}=-R_{r} \mathbf{i}_{q d r}+\mathbf{J} \omega_{r} \boldsymbol{\lambda}_{q d r} \\
\frac{d \lambda_{c c}}{d t}=-R_{s} \boldsymbol{\mu}_{q d}^{\mathrm{T}} \mathbf{i}_{q d s}+\left(\left\|\boldsymbol{\mu}_{q d}\right\| R_{s}+R_{f}\right) i_{f}
\end{array}\right. \\
& \left\{\begin{array}{l}
\mathbf{i}_{q d s}=\frac{L_{r}}{\nabla} \boldsymbol{\lambda}_{q d s}-\frac{L_{m}}{\nabla} \boldsymbol{\lambda}_{q d r}+\frac{2}{3} \boldsymbol{\mu}_{q d} i_{f} \\
\mathbf{i}_{q d r}=\frac{L_{s}}{\nabla} \boldsymbol{\lambda}_{q d r}-\frac{L_{m}}{\nabla} \boldsymbol{\lambda}_{q d s} \\
i_{f}=\frac{\lambda_{c c}-\boldsymbol{\mu}_{q d}^{\mathrm{T}} \boldsymbol{\lambda}_{q d s}}{\left(\frac{2}{3}\left\|\boldsymbol{\mu}_{q d}\right\|-1\right)\left\|\boldsymbol{\mu}_{q d}\right\| L_{l s}}
\end{array}\right.
\end{aligned}
$$

where $\boldsymbol{\lambda}_{q d s}, \boldsymbol{\lambda}_{q d r}$, and $\lambda_{c c}$ are the stator, rotor, and shortcircuited windings fluxes, respectively, in the $q d$ frame. $\mathbf{v}_{q d s}$, $\mathbf{i}_{q d s}, \mathbf{i}_{q d r}$, and $i_{f}$ represent the stator voltage and the stator, rotor, and fault currents, respectively, in the $q d$ frame. $R_{s}, R_{r}$, and $R_{f}$ are the stator, rotor, and fault resistances, respectively. $L_{s}, L_{r}$, and $L_{m}$ represent the stator, rotor, and magnetizing inductances, respectively. $\omega_{r}$ is the rotor speed,

$$
\begin{gathered}
\mathbf{J}=\left[\begin{array}{cc}
0 & -1 \\
1 & 0
\end{array}\right], \\
L_{l s}=L_{s}-L_{m}, \text { and } \nabla=L_{r} L_{s}-L_{m}^{2} . \\
\text { Mechanical dynamics is given by } \\
\frac{d \omega_{r}}{d t}=\frac{T_{E}}{J}-\frac{T_{L}}{J}-\frac{B}{J} \omega_{r}
\end{gathered}
$$

where $J$ is the inertia, $B$ is the viscous friction, $T_{L}$ is the load torque, and $T_{E}$ is the electromagnetic torque

$$
T_{E}=L_{m} P\left(\frac{3}{2} \mathbf{i}_{q d s} \times \mathbf{i}_{q d r}+i_{f} \boldsymbol{\mu}_{q d} \times \mathbf{i}_{q d r}\right) \hat{k}
$$

where $P$ is the number of pole pairs and $\hat{k}=\left[\begin{array}{lll}0 & 0 & 1\end{array}\right]^{\mathrm{T}}$.

\section{Proposed Strategy for Stator-Fault DETECTION AND IDENTIFICATION}

For correct detection and identification of interturn stator faults, an appropriate residual must be generated. Such residual 


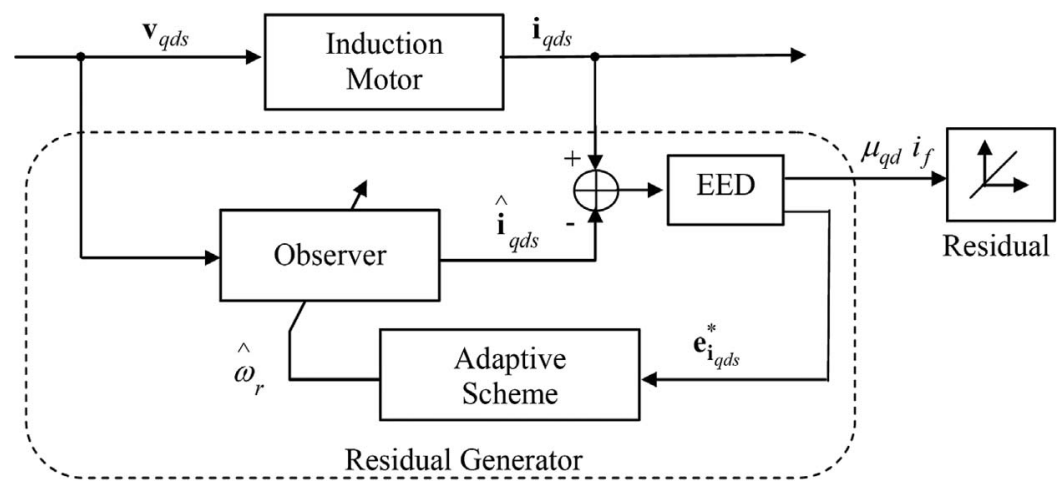

Fig. 2. Proposed detection and identification strategies.

must be able to rapidly reflect the changes produced by the fault over the normal operation, in order to obtain an immediate detection. In addition, the residual must allow a correct identification of the fault (diagnosis), minimizing the effect of external disturbances [25].

For rapid detection, a state observer based on the dynamic IM model is proposed in this paper. This observer constitutes the normal-operation model, which, when compared with the actual motor condition, allows the residual to be obtained from a decomposition of the current estimation error. This decomposition allows minimization of the effects of parameter variations and external disturbances. The selection of a vectorial residual allows a correct detection of the fault, independently of the faulted motor phase.

The proposed strategy is shown in Fig. 2. The residual generator uses the voltage and current measurement to feed the observer which estimates the stator and rotor fluxes and the stator currents. The current estimation error is decomposed (EED block in Fig. 2) into two terms, the first one is used to generate the vectorial residual, and the second term allows the improvement of the observer convergence and the rotorspeed estimation by means of an adaptive scheme. In the next sections, these blocks are described.

\section{A. State Observer}

A state observer, based on a "normal-operation model" [23] of the IM is used to generate the residual when compared with the actual motor. By defining

$$
\mathbf{i}_{q d s}^{\prime}=\mathbf{i}_{q d s}-\frac{2}{3} \boldsymbol{\mu}_{q d} i_{f}
$$

the following observer is proposed:

$$
\begin{aligned}
& \left\{\begin{array}{l}
\frac{d \hat{\boldsymbol{\lambda}}_{q d s}}{d t}=\mathbf{v}_{q d s}-R_{s} \hat{\mathbf{i}}_{q d s}^{\prime} \\
\frac{d \hat{\boldsymbol{\lambda}}_{q d r}}{d t}=-R_{r} \hat{\mathbf{i}}_{q d r}+\mathbf{J} \hat{\omega}_{r} \hat{\boldsymbol{\lambda}}_{q d r}
\end{array}\right. \\
& \left\{\begin{array}{l}
\hat{\mathbf{i}}_{q d s}^{\prime}=\frac{L_{r}}{\nabla} \hat{\boldsymbol{\lambda}}_{q d s}-\frac{L_{m}}{\nabla} \hat{\boldsymbol{\lambda}}_{q d r} \\
\hat{\mathbf{i}}_{q d r}=\frac{L_{s}}{\nabla} \hat{\boldsymbol{\lambda}}_{q d r}-\frac{L_{m}}{\nabla} \hat{\boldsymbol{\lambda}}_{q d s} .
\end{array}\right.
\end{aligned}
$$

Fault detection and identification are performed through the processing of the estimation error. When a stator fault occurs, the estimation error is given by

$$
\mathbf{e}_{\mathbf{i}_{q d s}}=\mathbf{i}_{q d s}-\hat{\mathbf{i}}_{q d s}^{\prime}=\frac{2}{3} \boldsymbol{\mu}_{q d} i_{f}+\mathbf{e}_{\mathbf{i}_{q d s}^{*}}^{*}
$$

where $\mathbf{e}_{\mathbf{i}_{q d s}}^{*}$ represents the estimation error produced by initial condition errors or parameter errors. If this term is null, then the estimation error is a direct indicator of the stator faults. However, to avoid false alarms produced by parameter errors or other perturbations that affect the estimation error, it has to be decomposed to extract the fault information.

A similar approach was presented in [20], where an adaptive observer was used to estimate the amount of short-circuited turns. However, since this adaptive observer was designed for a fault on the motor phase $a$, if a fault occurs in any of the other phases, it cannot be detected by such observer. Therefore, a set of three adaptive observers, one for each motor phase, is needed to take into account all the possible stator faults. In addition, parameter errors may produce false alarms in such strategy.

As shown in the next sections, these problems are overcome by the strategy proposed in this paper through the use of a vectorial residual and the error-decomposition scheme.

\section{B. Analysis of Estimation Error}

Estimation error can be analyzed in steady state, evaluating the model given by (4) and (5) under sinusoidal steady-state excitation. In order to consider the unbalanced operation produced by the fault or the unbalanced excitation, each variable $f$ can be expressed as the sum of two complex exponentials [26]

$$
f=\frac{1}{2} \tilde{F} e^{j \omega_{e} t}+\frac{1}{2} \tilde{F}^{*} e^{-j \omega_{e} t}
$$

where $\tilde{F}$ is the peak-value phasor. In addition, the vector $\mathbf{f}_{q d}$ can be expressed in complex vector form

$$
\mathbf{f}_{q d}=\tilde{F}_{p} e^{j \omega_{e} t}+\tilde{F}_{n}^{*} e^{-j \omega_{e} t}
$$

where $\tilde{F}_{p}$ and $\tilde{F}_{n}$ are the positive- and negative-sequence component phasors, respectively. 
By using (12) and (13), the IM model with stator fault in steady state results in

$$
\begin{aligned}
\tilde{V}_{s p} & =\left(R_{s}+j \omega_{e} L_{s}\right)\left(\tilde{I}_{s p}-\frac{1}{3} \boldsymbol{\mu} \tilde{I}_{f}\right)+j \omega_{e} L_{m} \tilde{I}_{r p} \\
\tilde{V}_{s n} & =\left(R_{s}+j \omega_{e} L_{s}\right)\left(\tilde{I}_{s n}-\frac{1}{3} \boldsymbol{\mu}^{*} \tilde{I}_{f}\right)+j \omega_{e} L_{m} \tilde{I}_{r n} \\
0 & =\left(\frac{R_{r}}{s}+j \omega_{e} L_{r}\right) \tilde{I}_{r p}+j \omega_{e} L_{m}\left(\tilde{I}_{s p}-\frac{1}{3} \boldsymbol{\mu} \tilde{I}_{f}\right) \\
0 & =\left(\frac{R_{r}}{2-s}+j \omega_{e} L_{r}\right) \tilde{I}_{r n}+j \omega_{e} L_{m}\left(\tilde{I}_{s n}-\frac{1}{3} \boldsymbol{\mu}^{*} \tilde{I}_{f}\right)
\end{aligned}
$$

where $\tilde{V}_{s p}, \tilde{V}_{s n}, \tilde{I}_{s p}$, and $\tilde{I}_{s n}$ are the positive- and negativesequence component phasors of the stator voltages and currents. $\tilde{I}_{r p}$ and $\tilde{I}_{r n}$ are the positive- and negative-sequence components phasors of the rotor currents. $\tilde{I}_{f}$ is the phasor of the fault current, $\omega_{e}$ is the excitation frequency, and $s$ is the slip. It must be noted that this steady state model is very similar to the one presented in [12], with a difference in the definition of the vector fault $\boldsymbol{\mu}$, which, in this case, is a complex magnitude that allows taking the faulted phase into account

$$
\begin{aligned}
\left.\boldsymbol{\mu}\right|_{a} & =\mu_{a} \\
\left.\boldsymbol{\mu}\right|_{b} & =\left(-\frac{1}{2}+j \frac{\sqrt{3}}{2}\right) \mu_{b}=a \mu_{b} \\
\left.\boldsymbol{\mu}\right|_{c} & =\left(-\frac{1}{2}-j \frac{\sqrt{3}}{2}\right) \mu_{c}=a^{2} \mu_{c}
\end{aligned}
$$

with $a=e^{j 2 \pi / 3}$.

The equation for the short-circuit loop results in

$$
\boldsymbol{\mu}^{*} \tilde{V}_{s p}+\boldsymbol{\mu} \tilde{V}_{s n}=\left(R_{s}+j \omega_{e} L_{l s}\right)\left(1-\frac{2}{3}|\boldsymbol{\mu}|\right)|\boldsymbol{\mu}| \tilde{I}_{f}+R_{f} \tilde{I}_{f}
$$

and solving for the fault current

$$
\tilde{I}_{f}=\frac{\frac{\boldsymbol{\mu}^{*}}{|\boldsymbol{\mu}|} \tilde{V}_{s p}+\frac{\boldsymbol{\mu}}{|\boldsymbol{\mu}|} \tilde{V}_{s n}}{\left(\left(R_{s}+j \omega_{e} L_{l s}\right)\left(1-\frac{2}{3}|\boldsymbol{\mu}|\right)+\frac{R_{f}}{|\boldsymbol{\mu}|}\right)} .
$$

By defining the fault impedance as

$$
Z_{f}=\left(R_{s}+j \omega_{e} L_{l s}\right)\left(1-\frac{2}{3}|\boldsymbol{\mu}|\right)+\frac{R_{f}}{|\boldsymbol{\mu}|}
$$

the fault current results in

$$
\tilde{I}_{f}=\frac{\boldsymbol{\mu}^{*}}{|\boldsymbol{\mu}|} \frac{\tilde{V}_{s p}}{Z_{f}}+\frac{\boldsymbol{\mu}}{|\boldsymbol{\mu}|} \frac{\tilde{V}_{s n}}{Z_{f}} .
$$

From the steady state motor equations (14)-(17) and the fault current (24), the positive- and negative-sequence stator currents can be found as a function of the excitation voltage

$$
\begin{aligned}
& \tilde{I}_{s p}=\left(\frac{1}{Z_{p}}+\frac{1}{3 Z_{f}}|\boldsymbol{\mu}|\right) \tilde{V}_{s p}+\frac{1}{3 Z_{f}} \boldsymbol{\mu}^{*} \tilde{V}_{s n} \\
& \tilde{I}_{s n}=\left(\frac{1}{Z_{n}}+\frac{1}{3 Z_{f}}|\boldsymbol{\mu}|\right) \tilde{V}_{s n}+\frac{1}{3 Z_{f}} \boldsymbol{\mu} \tilde{V}_{s p}
\end{aligned}
$$

where

$$
\begin{aligned}
& Z_{p}=\left(R_{s}+j \omega_{e} L_{s}\right)+\frac{\omega_{e}^{2} L_{m}^{2}}{\left(\frac{R_{r}}{s}+j \omega_{e} L_{r}\right)} \\
& Z_{n}=\left(R_{s}+j \omega_{e} L_{s}\right)+\frac{\omega_{e}^{2} L_{m}^{2}}{\left(\frac{R_{r}}{2-s}+j \omega_{e} L_{r}\right)} .
\end{aligned}
$$

On the other hand, the estimated currents based on the "normal-operation model" are given by

$$
\begin{aligned}
& \hat{\tilde{I}}_{s p}^{\prime}=\frac{\tilde{V}_{s p}}{\hat{Z}_{p}} \\
& \hat{\tilde{I}}_{s n}^{\prime}=\frac{\tilde{V}_{s n}}{\hat{Z}_{n}}
\end{aligned}
$$

where $\hat{Z}_{p}$ and $\hat{Z}_{n}$ stand for the nominal or estimated values of the motor parameters. This allows us to consider the influence of parameter errors due to temperature or load variation.

Then, the estimation error $e_{I s}=\tilde{I}_{s}-\hat{\tilde{I}}_{s}^{\prime}$ will be given by

$$
\begin{aligned}
& e_{I s p}=\left(\frac{1}{Z_{p}}-\frac{1}{\hat{Z}_{p}}\right) \tilde{V}_{s p}+\frac{1}{3 Z_{f}}\left(|\boldsymbol{\mu}| \tilde{V}_{s p}+\boldsymbol{\mu}^{*} \tilde{V}_{s n}\right) \\
& e_{I s n}=\left(\frac{1}{Z_{n}}-\frac{1}{\hat{Z}_{n}}\right) \tilde{V}_{s n}+\frac{1}{3 Z_{f}}\left(|\boldsymbol{\mu}| \tilde{V}_{s n}+\boldsymbol{\mu} \tilde{V}_{s p}\right) .
\end{aligned}
$$

As it can be seen in (29) and (30), the first term corresponds to the error produced by parameter errors [ $\mathbf{e}_{\mathbf{i}_{q d s}^{*}}^{*}$ in (11)], while the second one is the error introduced by the stator fault.

If it is assumed that the motor parameters are exactly known, the first terms in (29) and (30) can be neglected. Then, both the negative- and positive-sequence error could be used for statorfault detection [16].

However, parameter errors may occur due to temperature variation, saturation, or other disturbances. In such a case, it must be noted that in the positive-sequence error $\left(e_{I s p}\right)$, the parametric error is multiplied by the positive-sequence voltage, so its influence over the estimation error is very important. On the other hand, in the negative-sequence error $\left(e_{I s n}\right)$, the error produced by parameter variation is multiplied by the negative-sequence voltage which, in normal conditions, must be lower than $5 \%$ of the positive-sequence voltage. Therefore, the negative-sequence estimation error can be used to detect the stator fault, since it is practically insensitive to parameter errors or load variation. Even in the case of voltage unbalance, the negative-sequence impedance is practically independent of the load and speed variation for open-rotor-slot motors (less than $8 \%$ from no-load to full-load, for the tested motor). Consequently, its influence on the negative-sequence error can also be neglected in such a case. For motors with closedrotor-slot construction (usually small power motors), where the 
negative-sequence impedance variation could introduce a more significant error, this effect can be compensated in the negativesequence component of the estimation error through a motor characterization, as proposed in [13].

Thus, neglecting the terms that involve the negative-sequence voltage, the sequence components of the estimation error results

$$
\begin{aligned}
e_{I s p} & =\left(\frac{1}{Z_{p}}-\frac{1}{\hat{Z}_{p}}\right) \tilde{V}_{s p}+\frac{1}{3 Z_{f}}\left(|\boldsymbol{\mu}| \tilde{V}_{s p}\right) \\
e_{I s n} & =\frac{1}{3 Z_{f}}\left(\boldsymbol{\mu} \tilde{V}_{s p}\right)
\end{aligned}
$$

where it is clear that the information about the faulted phase (angle of $\boldsymbol{\mu}$ ) remains in the negative-sequence component of the error, but there is no such information in the positive-sequence component. The angle of the faulted phase is needed for a correct reconstruction of the error produced by parameter and speed variations, which is used for speed adaptation.

\section{Fault Detection and Identification}

As stated before, the aim of stator-fault monitoring is to detect the fault as early as possible, while avoiding false alarms. In this paper, both objectives are achieved by using the negativesequence component of the estimation error. The steady-state current error can also be obtained as a function of the fault current, from (14)-(17), and neglecting the negative-sequence voltage

$$
\begin{aligned}
& e_{I s p}=\left(\frac{1}{Z_{p}}-\frac{1}{\hat{Z}_{p}}\right) \tilde{V}_{s p}+\frac{1}{3} \boldsymbol{\mu} \tilde{I}_{f} \\
& e_{I s n}=\frac{1}{3} \boldsymbol{\mu}^{*} \tilde{I}_{f} .
\end{aligned}
$$

As it can be seen, the negative-sequence component is proportional to the fault current and the number of shortcircuited turns, but it is practically independent of parameter errors, which makes it a reliable fault detector. By using this component for fault detection, it is possible to detect incipient faults, either due to the increase of the fault current or the number of short-circuited turns. The use of this fault detector also allows us to avoid false alarms due to parameter errors or load and speed variations, as shown in the previous section.

For online monitoring, a proper choice of a fault severity allows us to set some alarm levels, thus allowing the automatic disconnection of the motor in order to avoid severe damages. Since the effect of the fault over the motor current is completely represented by the term $\boldsymbol{\mu}_{q d} i_{f}$, its normalized modulus is used in this paper as a severity factor (a similar severity factor was used in [16])

$$
\text { Severity factor }=\frac{\left|\boldsymbol{\mu}_{q d} i_{f}\right|}{\sqrt{2} I_{\text {nom }}}
$$

where $I_{\text {nom }}$ is the nameplate rms value of the motor current. It must be noted that $\left|\boldsymbol{\mu}_{q d} i_{f}\right|$, calculated from the output of the EED block, includes the peak value of $i_{f}$.

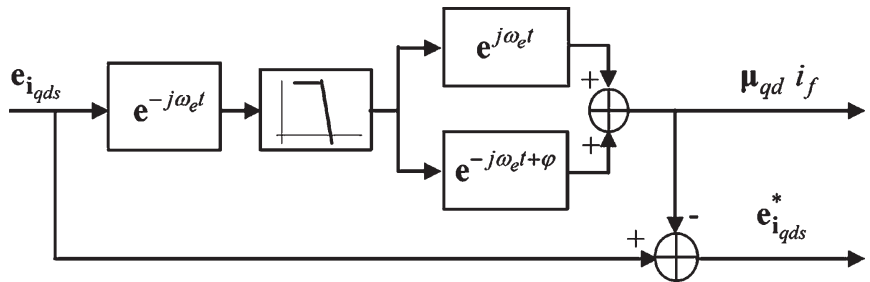

Fig. 3. Estimation-error decomposition.

\section{Estimation-Error Decomposition}

As shown in the previous section, the component of the estimation error produced by the fault can be determined from the negative-sequence component of the estimation error. This negative-sequence component can be extracted from the estimation error by means of a reference frame rotating with inverse sequence. As soon as a stator fault occurs, it is detected by this negative-sequence error component.

From this component, the complete fault signal $\left((2 / 3) \boldsymbol{\mu}_{q d} i_{f}\right)$ can also be reconstructed. This signal can be used to cancel the component of the estimation error produced by the fault, obtaining the error produced by parameter errors $\left(\mathbf{e}_{\mathbf{i}_{q d s}}^{*}\right)$. Such an error can be used for rotor-speed estimation.

Fig. 3 shows a block diagram of the proposed estimationerror-decomposition scheme. In order to isolate the error produced by the fault, the error signal is projected to a reference frame rotating with inverse sequence. In this frame, the negative-sequence component results in a dc signal, while the positive-component will be a double-frequency ac signal. Then, the negative-sequence component can be easily separated by using a low-pass filter.

Once the negative-sequence component is obtained, the positive-sequence component of the error produced by the fault can be reconstructed. It has the same magnitude of the negativesequence component, as shown by (31) and (32), but its angle is different, since it does not include the information of the faulted phase. This angle $(\varphi)$ is obtained from the negative-sequence angle, subtracting the angle of the faulted phase.

The information about the faulted phase is obtained from the negative-sequence component of the estimation error (32). As it can be seen, its angle is determined by the positivesequence voltage component, the fault impedance, and the angle of $\boldsymbol{\mu}\left(\phi_{\boldsymbol{\mu}}\right)$. Since the angle of the positive-sequence voltage component $\left(\phi_{V_{s}}\right)$ is known and the angle of the fault impedance $\left(\phi_{Z_{f}}\right)$ is less than or equal to the angle of the stator impedance [depending on the value of $R_{f}$, see (23)], the angle of the faulted phase can be approximated as

$$
\phi_{\boldsymbol{\mu}} \approx \phi_{e_{I s n}}-\left(\phi_{V_{s}}-\phi_{Z_{f}}\right)
$$

where $\phi_{e_{I s n}}$ is the angle of $e_{I s n}$. This angle will be close to $0,2 \pi / 3$, or $4 \pi / 3$ if the fault occurs in phase $a, b$, or $c$, respectively.

Then, the complete fault signal $\boldsymbol{\mu}_{q d} i_{f}$ is reconstructed and canceled from the estimation error. The component $\mathbf{e}_{\mathbf{i}_{q d s}}^{*}$ is used into the adaptive scheme to obtain the rotor speed. 
TABLE I

IM DATA

\begin{tabular}{|c|c||c|c|}
\hline $5.5 \mathrm{~kW}$ & 4 poles & $380 \mathrm{~V}$ & $11 \mathrm{~A}$ \\
\hline \hline stator windings & & connection & series \\
\hline turns/windings & 18 & windings/group & 2 \\
\hline groups/phase & 4 & step & $1: 10: 12$ \\
\hline \hline$R_{s}$ & $0.95 \Omega$ & $R_{r}$ & $0.36 \Omega$ \\
\hline$L_{l s}=L_{l r}$ & $4.7 \mathrm{mH}$ & $L_{m}$ & $122 \mathrm{mH}$ \\
\hline
\end{tabular}

\section{E. Rotor-Speed Estimation}

As can be seen in (9) and (10), the proposed observer needs the information about the rotor speed for a correct estimation of the stator flux and currents. The rotor speed can be estimated by using an adaptive scheme, as proposed in [27]. Considering that the rotor speed varies slowly and using the corrected current estimation error $\left(\mathbf{e}_{\mathbf{i}_{q d s}}^{*}\right)$, the estimated rotor speed is given by

$$
\hat{\omega}_{r}=K_{1}\left(\mathbf{e}_{\mathbf{i}_{q d s}}^{*} \times \hat{\boldsymbol{\lambda}}_{q d r}\right) \hat{k}+K_{2} \int\left(\mathbf{e}_{\mathbf{i}_{q d s}^{*}}^{*} \times \hat{\boldsymbol{\lambda}}_{q d r}\right) \hat{k} d t
$$

where $K_{1}$ and $K_{2}$ are constants.

The use of the estimated speed in the proposed observer avoids the use of a speed sensor, which is needed in some previously proposed model-based strategies [16], [22]. This allows the implementation of the proposed technique for online monitoring using only current and voltage measurements.

\section{EXPERIMENTAL RESULTS}

The proposed strategy was validated through experimental results. An IM with modified stator windings (Table I), which allows us to short circuit different number of turns of each phase winding, was used. To avoid a permanent damage of the motor windings, all the experiments were performed with reduced supply voltage and for a short time. A small resistance was also used to limit the short-circuit current.

Since the main objective of online-detection strategies is the fast detection of incipient faults, two types of incipient faults are first considered. The first one corresponds to a short circuit of only three turns $(2.08 \%)$ of the winding, while the second one corresponds to a fault with a very low fault current circulating through the short-circuited turns.

The results obtained for a short circuit of $2.08 \%$ of phase $a$ winding of the unloaded motor are shown in Fig. 4. The fault current was limited to $63.6 \mathrm{~A}$ (peak) through a $27-\mathrm{m} \Omega$ resitance and a 300-V supply voltage. Fig. 4(a) shows the severity factor estimated by the proposed strategy, where it can be seen that the fault is rapidly detected and identified through the great difference between the nonfault and fault states. The norm of the error between the motor current and the estimated current is shown in Fig. 4(b). The norm of the current estimation error, once the error component produced by the fault is canceled, is shown in Fig. 4(c). It can be clearly seen that the error component produced by the fault is fully canceled after a short transient. This corrected error is used for speed estimation through the adaptive scheme.

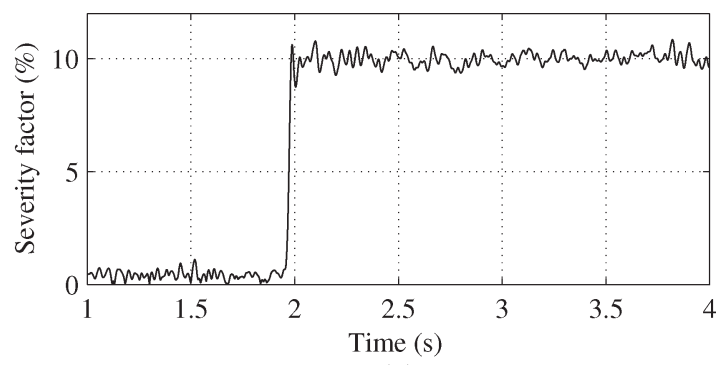

(a)

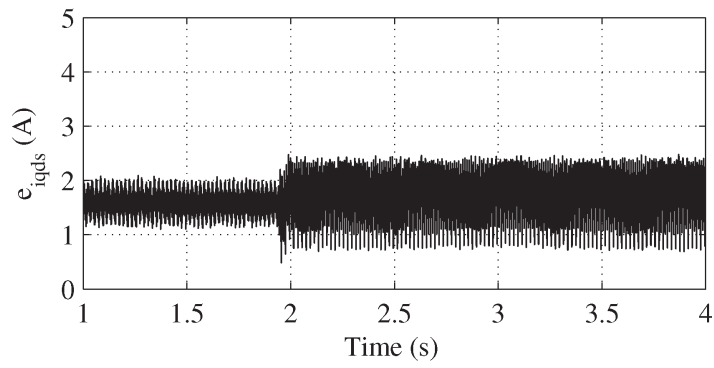

(b)

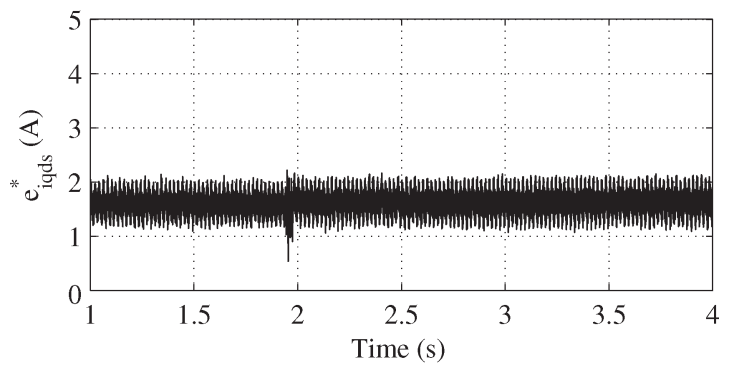

(c)

Fig. 4. Fault in motor phase a $(2.08 \%$, three turns), unloaded motor. (a) Estimated severity factor. (b) Norm of the current error. (c) Norm of the corrected current error.

As it was already mentioned, in the proposed strategy, an incipient fault can be detected independently of the phase in which the fault occurs. Such an advantage is shown in Fig. 5, where a similar fault $(2.08 \%$, three short-circuited turns) was produced in the windings of the each motor phase. Fig. 5(a) shows the results obtained with the short circuit produced in the motor phase $a$; Fig. 5(b) shows the results for the fault in the motor phase $b$, while Fig. 5(c) corresponds to the fault in the motor phase $c$. In each case, the severity factor and the estimated angle of $e_{I s n}\left(\phi_{e_{I s n}}\right)$ are presented. As it can be seen, the fault is properly detected in all the cases, independent of the phase in which the fault was produced. The angle $\phi_{e_{I s n}}$ validates (32) and allows the complete reconstruction of the fault signal, as shown in Fig. 5(d). In this figure, components $q d$ of the $\mu \hat{i}_{f}$ estimated (normalized) vector are presented in the $q-d$ plane. The angle of this vector $\left(\phi_{\boldsymbol{\mu}}\right)$ indicates the faulted phase.

The robustness of the proposed strategy against parameter variation is evaluated in Fig. 6, where a sudden variation in different observer parameters was produced at $t=1 \mathrm{~s}$. An increase of $25 \%$ on the value of $R_{s}$ is shown in Fig. 6(a). As it can be seen, this parameter variation introduces a very low perturbation in the estimated severity factor at $t=1 \mathrm{~s}$. However, such perturbation is not enough to produce a false alarm. 


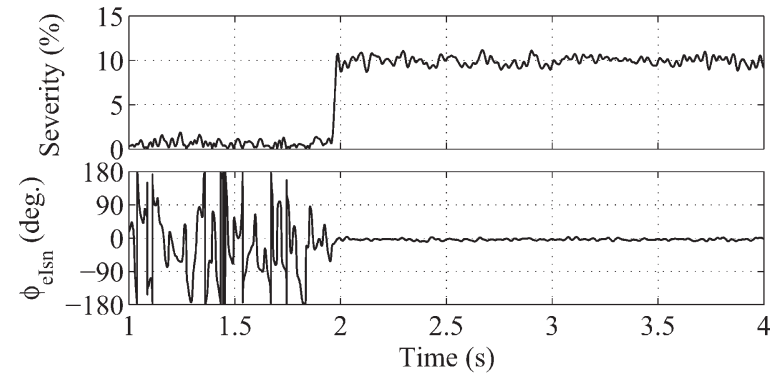

(a)

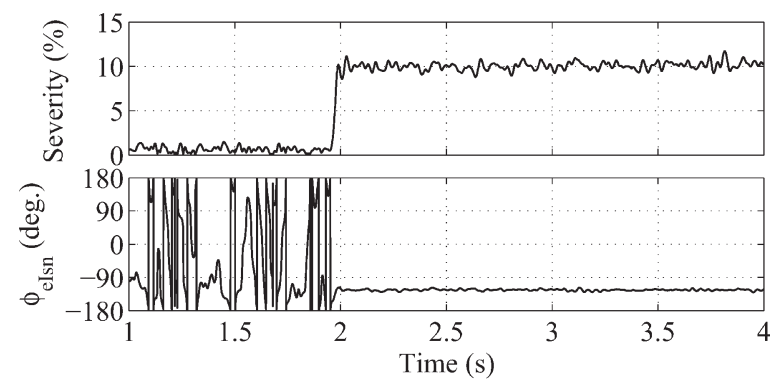

(b)

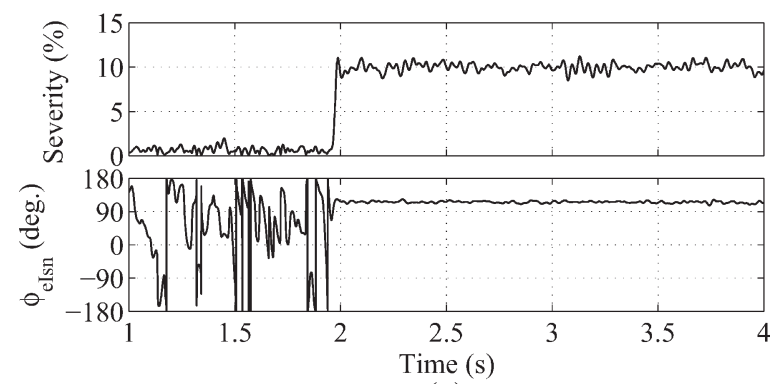

(c)

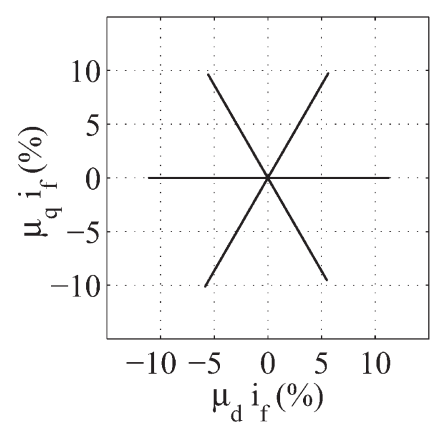

(d)

Fig. 5. Faults in each motor phase (2.08\%, three turns), unloaded motor. (a) Fault in phase $a$, (b) phase $b$, (c) phase $c$, and (d) normalized $\mu \hat{i}_{f}$.

Similar results are obtained for a change in $R_{r}$ [Fig. 6(b)] and $L_{m}$ [Fig. 6(c)], but in these cases, the perturbation is even lower.

Even in case of severe voltage unbalance, the proposed strategy is able to detect incipient faults. This property is shown in Fig. 7(a) and (b), where a short circuit of $2.08 \%$ of phase $a$ winding is produced on the unloaded and fully loaded motors, when the motor is supplied with unbalanced voltages $(4.2 \%$ and $4.8 \% \tilde{\mathrm{V}}_{\mathrm{sn}} / \tilde{\mathrm{V}}_{\mathrm{sp}}$ ), respectively. As stated before, the influence of voltage unbalance and load level is practically neglectable, as shown in Fig. 7(c). As it can be seen, the severity factor varies less than $1 \%$ in the whole range of the allowed voltage unbalance.

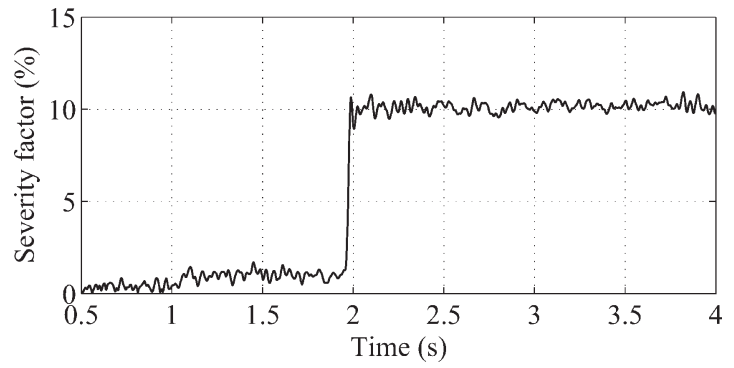

(a)

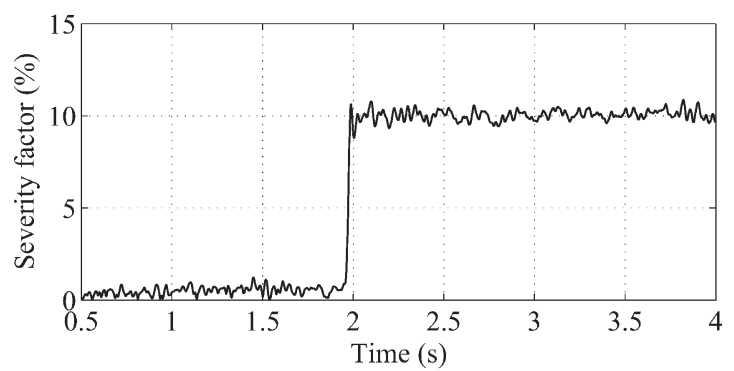

(b)

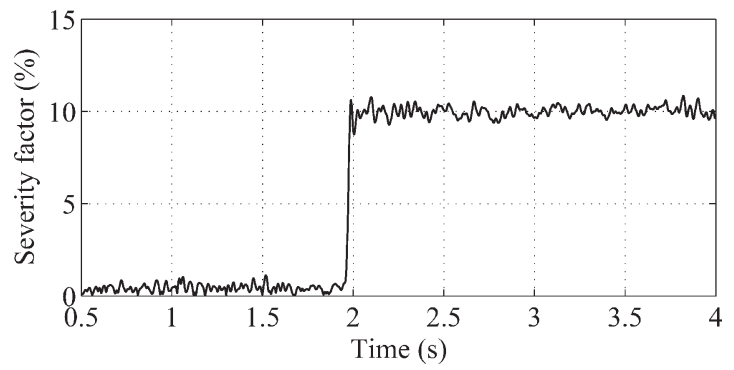

(c)

Fig. 6. Fault in motor phase $a(2.08 \%$, three turns $)$, unloaded motor. Estimated severity factor with (a) $25 \%$ variation of $R_{s}$ at $t=1 \mathrm{~s}$, (b) $50 \%$ variation of $R_{r}$ at $t=1 \mathrm{~s}$, and (c) $25 \%$ variation of $L_{m}$ at $t=1 \mathrm{~s}$.

The sensitivity of the proposed method to nonmodeled motor or measurement asymmetries is the same as other methods based on sequence-component errors (e.g., [16]), since such asymmetries affect the motor currents in the same way as the stator fault does. However, common motor asymmetries due to construction defects will only introduce some offset in the fault detector, which can be taken into account when setting the alarm levels.

Some strategies proposed in the literature have been proven to fail for detecting incipient faults, when the fault current is lower than the load current [28]. The proposed strategy is able to detect such type of faults, as shown in Fig. 8. In this case, an incipient fault is emulated by limiting the fault current to 7 A (9.9-A peak), for a short circuit of ten turns $(6.94 \%)$ on the phase $a$ winding. Results are shown for the unloaded motor and for the motor consuming the nominal current (11 A) at the reduced supply voltage in Fig. 8(a) and (b), respectively. Even when the estimated severity factor seems noisy for the loaded motor, the fault is still clearly detected when the fault current is low. This situation could correspond to a fault that begins with a high-resistance contact between turns, owing to dust or moisture.

Next, different situations were tested, and the obtained results are shown in Figs. 9 and 10. Fig. 9 corresponds to the 


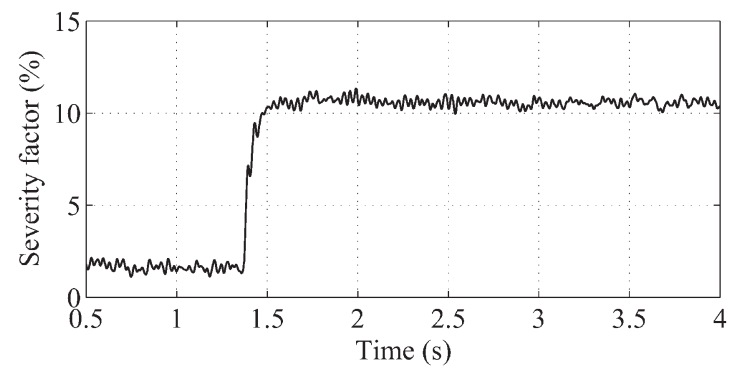

(a)

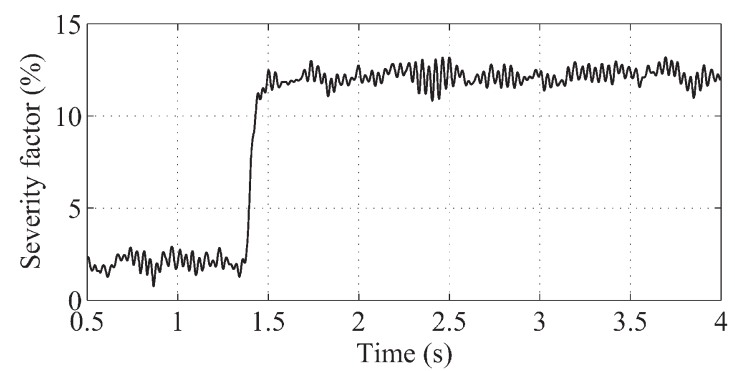

(b)

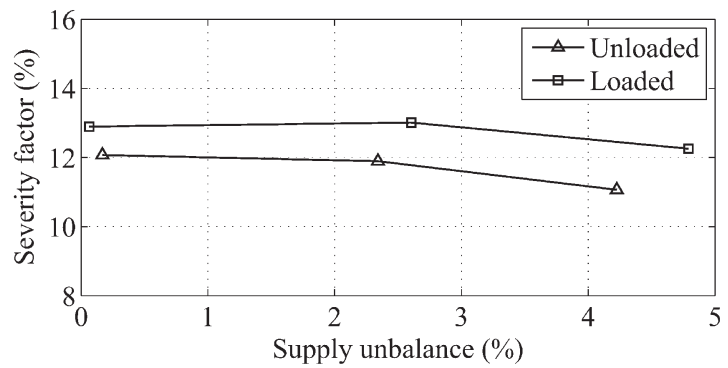

(c)

Fig. 7. Fault in motor phase $a(2.08 \%$, three turns). Estimated severity factor with (a) $4.2 \%$ supply unbalance, unloaded motor, (b) $4.8 \%$ supply unbalance, fully loaded motor, and (c) different values of supply unbalance.

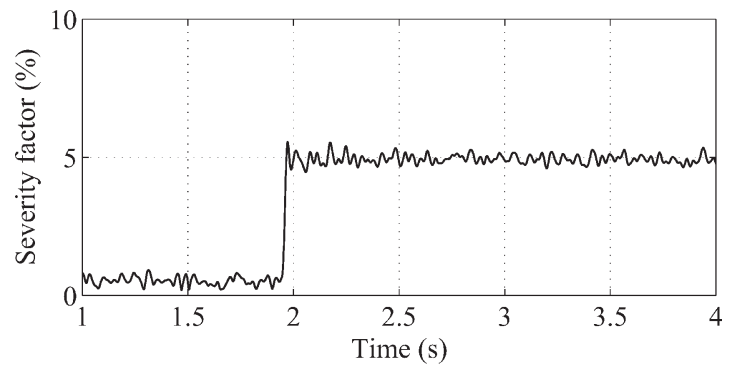

(a)

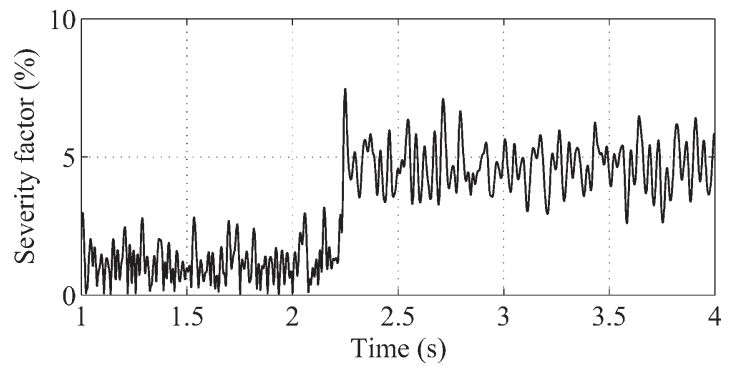

(b)

Fig. 8. Fault in motor phase $a$ (6.94\%, ten turns), 7-A (9.9-A peak) fault current. (a) Unloaded motor. (b) Loaded motor, 11-A load current.

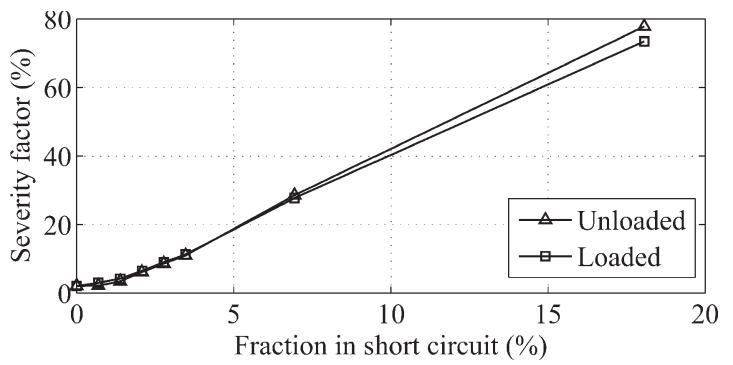

(a)

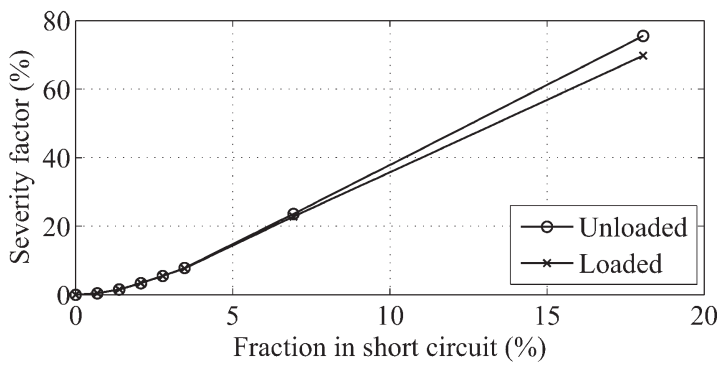

(b)

Fig. 9. Fault in motor phase a. (a) Estimated severity factor. (b) Calculated severity factor.

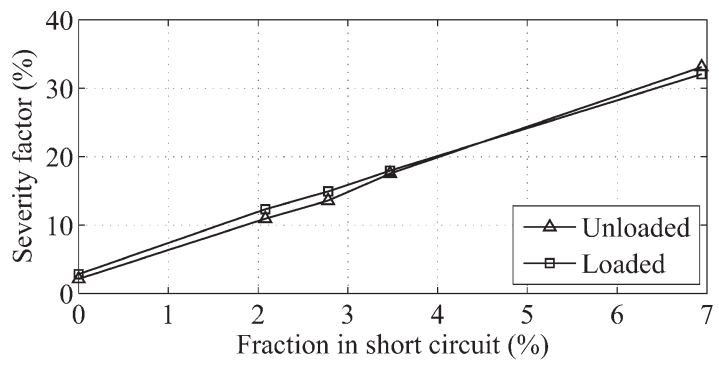

(a)

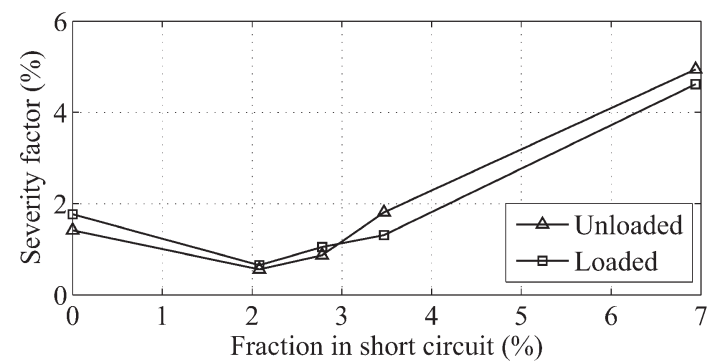

(b)

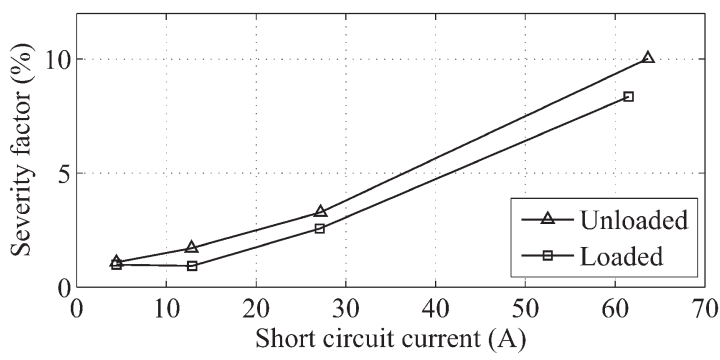

(c)

Fig. 10. Estimated severity factor for different faults in motor phase $a$. (a) 60-A (peak) fault current. (b) 10-A (peak) fault current. (c) short circuit of three turns. 
motor running with reduced supply voltage $(125 \mathrm{~V})$ and a fault-resistance value of $27 \mathrm{~m} \Omega$. Several interturn faults were produced, increasing the number of turns from 0 (no fault) to 26 turns (18.06\% of the winding). These tests were performed for the motor running with load (11-A load current) and without load. For such conditions, the estimated severity factor is shown in Fig. 9(a). This severity factor was obtained in the same way as in the previous experiments; i.e., once a change in the fault signal was detected. Its value allows the evaluation of the range in which the fault is detectable. Since the modified motor allows the measurement of the fault current, the actual severity factor was calculated for each fault, and the results are shown in Fig. 9(b). As shown, the estimated severity factor is in good agreement with the actual one, in the whole range of faults. It must be noted that, in these tests, the fault current grows as the number of short-circuited turns is increased.

Two tests were performed for a constant value of the fault current, while changing the number of short-circuited turns. The results for high fault current (60-A peak) are shown in Fig. 10(a), for the motor with and without load. As shown, for this value of fault current (almost four times the nominal current), the fault is easily detected even with only three turns short-circuited. Fig. 10(b) shows the results for a very low fault current (10-A peak), emulating an incipient fault. In this situation, the fault can be detected for above $3.5 \%$ of the winding (five turns) in short circuit. Finally, Fig. 10(c) shows the estimated severity factor when the short circuit occurs in three adjacent turns (2.08\% of the winding) for different values of the short-circuit current. In this case, the supply voltage was fixed at $318 \mathrm{~V}$, while the fault resistance was changed to limit the fault current to the different values (from 4.5- to 63.6-A peak). Fig. 10(c) clearly shows that the stator fault can be detected beginning from 12.9-A peak.

From Fig. 10, it can be concluded that it is possible to detect a stator fault involving a few short-circuited turns if the fault current is high (near to the load current), while a fault with a lower fault current can be detected if the number of shortcircuited turns is higher.

\section{CONClusion}

A new model-based strategy for stator-fault detection and identification of IM is presented in this paper. This strategy uses a state observer which generates a vector of specific residuals, allowing for the rapid detection of an incipient fault, independently of the phase in which the fault occurs. The negative-sequence component of the current estimation error, obtained through an estimation-error decomposition, is used as a fault detector. From the analysis, it is shown that the use of this component allows a correct fault detection while avoiding false alarms produced by parameter or load variations.

The error-decomposition scheme also allows a correct identification of the faulted phase, which is necessary to decouple the effects of the fault from the estimation error. Thus, a corrected estimation error is used in an adaptive scheme for speed estimation, avoiding the use of a speed sensor, which is required in some previously presented strategies.
The strategy is experimentally evaluated under different fault and load conditions. Fault conditions include short circuits in different motor phases, different numbers of shorted turns, and different values of fault current. The effects of parameter variation and voltage unbalance were also experimentally evaluated. It is shown that the proposed technique is able to rapidly detect very incipient faults, from about $2 \%$ of the winding in short circuit. The ability to detect faults when the fault current is lower than the load current, representing a fault that begins with high contact resistance, is also shown.

\section{REFERENCES}

[1] A. Bellini, F. Filippetti, C. Tassoni, and G. A. Capolino, "Advances in diagnostic techniques for induction machines," IEEE Trans. Ind. Electron., vol. 55, no. 12, pp. 4109-4126, Dec. 2008.

[2] N. Arthur and J. Penman, "Induction machine condition monitoring with higher order spectra," IEEE Trans. Ind. Electron., vol. 47, no. 5, pp. 10311041, Oct. 2000.

[3] H. Su and K. T. Chong, "Induction machine condition monitoring using neural network modeling," IEEE Trans. Ind. Electron., vol. 54, no. 1, pp. 241-249, Feb. 2007.

[4] H. Henao, C. Demian, and G.-A. Capolino, "A frequency-domain detection of stator winding faults in induction machines using an external flux sensor," IEEE Trans. Ind. Appl., vol. 39, no. 5, pp. 1272-1279, Sep./Oct. 2003.

[5] J. H. Jung, J. J. Lee, and B. H. Kwon, "Online diagnosis of induction motors using MCSA,” IEEE Trans. Ind. Electron., vol. 53, no. 6, pp. 18421852, Dec. 2006

[6] S. Grubic, J. M. Aller, B. Lu, and T. G. Habetler, "A survey on testing and monitoring methods for stator insulation systems of low-voltage induction machines focusing on turn insulation problems," IEEE Trans. Ind. Electron., vol. 55, no. 12, pp. 4127-4136, Dec. 2008.

[7] R. M. Tallam, S. B. Lee, G. C. Stone, G. B. Kliman, J. Yoo, T. G. Habetler, and R. G. Harley, "A survey of methods for detection of stator-related faults in induction machines," IEEE Trans. Ind. Appl., vol. 43, no. 4 , pp. 920-933, Jul./Aug. 2007.

[8] M. El Hachemi Benbouzid, "A review of induction motors signature analysis as a medium for faults detection," IEEE Trans. Ind. Electron., vol. 47, no. 5, pp. 984-993, Oct. 2000.

[9] S. H. Kia, H. Henao, and G. A. Capolino, "A high-resolution frequency estimation method for three-phase induction machine fault detection," IEEE Trans. Ind. Electron., vol. 54, no. 4, pp. 2305-2314, Aug. 2007.

[10] A. Bellini, A. Yazidi, F. Filippetti, C. Rossi, and G. A. Capolino, "High frequency resolution techniques for rotor fault detection of induction machines," IEEE Trans. Ind. Electron., vol. 55, no. 12, pp. 4200-4209, Dec. 2008.

[11] J. Cusido, L. Romeral, J. A. Ortega, J. A. Rosero, and A. García Espinosa, "Fault detection in induction machines using power spectral density in wavelet decomposition," IEEE Trans. Ind. Electron., vol. 55, no. 2, pp. 633-643, Feb. 2008.

[12] R. M. Tallam, T. G. Habetler, and R. G. Harley, "Transient model for induction machines with stator winding turn faults," IEEE Trans. Ind. Appl., vol. 38, no. 3, pp. 632-637, May/Jun. 2002.

[13] M. Arkan, D. K. Perovic, and P. Unsworth, "Online stator fault diagnosis in induction motors," Proc. Inst. Elect. Eng.-Elect. Power Appl., vol. 148 , no. 6 , pp. 537-547, Nov. 2001.

[14] S. Cruz and A. Cardoso, "Stator winding fault diagnosis in three-phase synchronous and asynchronous motors, by the extended Park's vector approach," IEEE Trans. Ind. Appl., vol. 33, no. 5, pp. 1227-1233, Sep./Oct. 2001

[15] S. B. Lee, R. Tallam, and T. Habetler, "A robust, on-line turn-fault detection technique for induction machines based on monitoring the sequence component impedance matrix," IEEE Trans. Power Electron., vol. 18, no. 3, pp. 865-872, May 2003.

[16] S. Cruz and A. Cardoso, "Multiple reference frames theory: A new method for the diagnosis of stator faults in three-phase induction motors," IEEE Trans. Energy Convers., vol. 20, no. 3, pp. 611-619, Sep. 2005.

[17] F. Filippetti, G. Franceschini, C. Tassoni, and P. Vas, "Recent developments of induction motor drives fault diagnosis using AI techniques," IEEE Trans. Ind. Electron., vol. 47, no. 5, pp. 994-1004, Oct. 2000 
[18] M. B. K. Bouzid, G. Champenois, N. M. Bellaaj, L. Signac, and K. Jelassi, "An effective neural approach for the automatic location of stator interturn faults in induction motor," IEEE Trans. Ind. Electron., vol. 55, no. 12, pp. 4277-4289, Dec. 2008.

[19] M. S. Ballal, Z. J. Khan, H. M. Suryawanshi, and R. L. Sonolikar, "Adaptive neural fuzzy inference system for the detection of interturn insulation and bearing wear faults in induction motor," IEEE Trans. Ind. Electron., vol. 54, no. 1, pp. 250-258, Feb. 2007.

[20] C. S. Kallesoe, R. Izadi-Zamanabadi, P. Vadstrup, and H. Rasmussen, "Observer-based estimation of stator-winding faults in delta-connected induction motors: A linear matrix inequality approach," IEEE Trans. Ind. Appl., vol. 43, no. 4, pp. 1022-1031, Jul./Aug. 2007.

[21] C. De Angelo, G. Bossio, S. Giaccone, G. O. Garcia, J. Solsona, and M. I. Valla, "Model based stator fault detection in induction motors," in Proc. 32nd Annu. Conf. IEEE Ind. Electron. Soc. IECON, Paris, France, Nov. 7-10, 2006, pp. 1095-1100.

[22] S. Bachir, S. Tnani, J. C. Trigeassou, and G. Champenois, "Diagnosis by parameter estimation of stator and rotor faults occurring in induction machines," IEEE Trans. Ind. Electron., vol. 53, no. 3, pp. 963-973, Jun. 2006.

[23] X. Chang, V. Cocquempot, and C. Christophe, "A model of asynchronous machines for stator fault detection and isolation," IEEE Trans. Ind. Electron., vol. 50, no. 3, pp. 578-584, Jun. 2003.

[24] G. M. Joksimovic and J. Penman, "The detection of interturn short circuits in the stator windings of operating motors," IEEE Trans. Ind. Electron., vol. 47 , no. 5 , pp. $1078-1084$, Oct. 2000 .

[25] R. Isermann, "Model-based fault detection and diagnosis-Status and applications (Plenary lecture)," in Proc. 16th IFAC Symp. Autom. Control Aerosp., St. Petersburg, Russia, Jun. 14-18, 2004.

[26] D. W. Novotny and T. A. Lipo, Vector Control and Dynamics of AC Drives. Oxford, U.K.: Clarendon, 1996

[27] H. Kubota, K. Matsuse, and T. Nakano, "DSP based speed adaptive flux observer of induction motor," IEEE Trans. Ind. Appl., vol. 29, no. 2, pp. 344-348, Mar./Apr. 1993.

[28] B. Mirafzal and N. A. O. Demerdash, "On innovative methods of induction motor interturn and broken-bar fault diagnostics," IEEE Trans. Ind. Appl., vol. 42, no. 2, pp. 405-414, Mar./Apr. 2006.

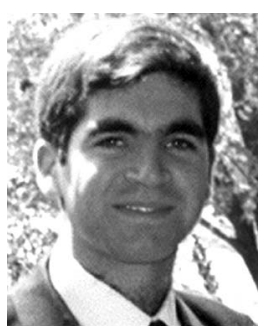

Cristian H. De Angelo (S'96-M'05) received the Electrical Engineer degree from the Universidad Nacional de Río Cuarto, Río Cuarto, Argentina, in 1999 and the Dr. of Engineering degree from the Universidad Nacional de La Plata, La Plata, Argentina, in 2004.

Since 1994, he has been with the Grupo de Electrónica Aplicada, Facultad de Ingeniería, Universidad Nacional de Río Cuarto. He is also currently with Consejo Nacional de Investigaciones Científicas y Técnicas, Argentina. His research interests include fault diagnosis on electric machines, sensorless motor control, electric vehicles, and renewable-energy generation.

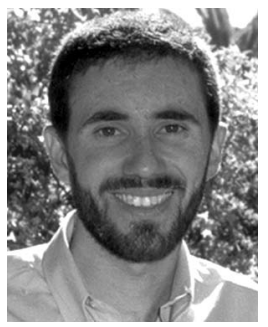

Guillermo R. Bossio (S'03-M'07) received the Electrical Engineer degree from the Universidad Nacional de Río Cuarto, Río Cuarto, Argentina, in 1999 and the Dr. of Engineering degree from the Universidad Nacional de La Plata, La Plata, Argentina, in 2004

Since 1994, he has been with the Grupo de Electrónica Aplicada, Facultad de Ingeniería, Universidad Nacional de Río Cuarto. He is also currently with Consejo Nacional de Investigaciones Científicas y Técnicas, Argentina. His research interests include fault diagnosis on electric machines, sensorless motor control, electric vehicles, and renewable-energy generation.

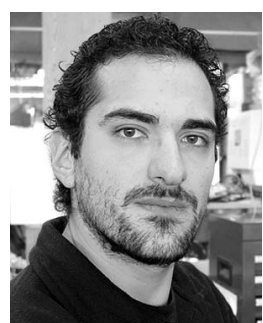

Santiago J. Giaccone received the Electrical Engineer degree from the Universidad Nacional de Río Cuarto, Río Cuarto, Argentina, in 2005. He is currently working toward the Dr. of Engineering degree at the Universidad Nacional del Sur, Bahía Blanca, Argentina.

Since 2001, he has been with the Grupo de Electrónica Aplicada, Facultad de Ingeniería, Universidad Nacional de Río Cuarto. He is also currently with Consejo Nacional de Investigaciones Científicas y Técnicas, Argentina. His research interests include fault detection in electric machines.

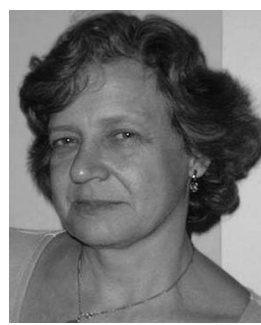

María Inés Valla (S'79-M'80-SM'97) received the Electronics Engineer and Doctor in Engineering degrees from National University of La Plata (UNLP), La Plata, Argentina, in 1980 and 1994, respectively.

She is currently a Full Professor with the Laboratorio de Electrónica Industrial, Control e Instrumentación, Departamento de Electrotecnia, Facultad de Ingeniería, UNLP. She is currently also with the Consejo Nacional de Investigaciones Científicas y Técnicas, Argentina. She is engaged in teaching and research in the areas of power converters and ac

motor drives.

Prof. Valla is a member of the Buenos Aires Academy of Engineering in Argentina. Within IEEE, she is a member of the Ethics and Membership Conduct Committee and a Senior Member of the Administrative Committee of the Industrial Electronics Society.

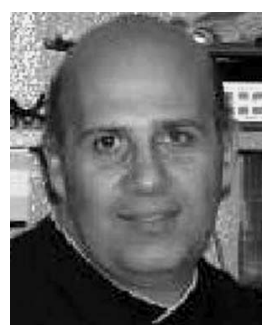

Jorge A. Solsona (S'94-M'96-SM'04) received the Electronics Engineer and Doctor in Engineering degrees from the Universidad Nacional de La Plata, La Plata, Argentina, in 1986 and 1995, respectively.

From 1987 to 1997, he was a member of the Laboratorio de Electrónica Industrial, Control e Instrumentación, Departamento de Electrotecnia, Facultad de Ingeniería, Universidad Nacional de La Plata. Between 1997 and 2003, he was with the Departamento de Electrotecnia, Facultad de Ingeniería, Universidad Nacional del Comahue, Neuquén, Argentina. He is currently with the Instituto de Investigaciones en Ingeniería Eléctrica "Alfredo Desages," Departamento de Ingeniería Eléctrica y Computadoras, Universidad Nacional del Sur, Bahía Blanca, Argentina. He is currently also with the Consejo Nacional de Investigaciones Científicas y Técnicas, Argentina. He is involved in teaching and research in control theory and its applications to electromechanical systems.

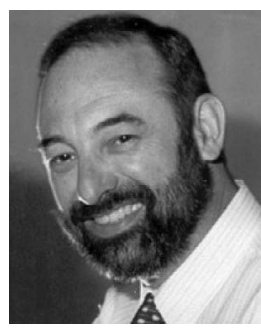

Guillermo O. García (S'90-M'95-SM'01) received the Electrical and Electronics Engineering degree from the Universidad Nacional de Córdoba, Córdoba, Argentina, in 1981 and the M.Sc. and Dr. degrees in electrical engineering from COPPE, Universidade Federal do Rio de Janeiro, Rio de Janeiro, Brazil, in 1990 and 1994, respectively.

Since 1994, he has been with the Universidad Nacional de Río Cuarto, Río Cuarto, Argentina, where he is currently the Director of the Grupo de Electrónica Aplicada, Facultad de Ingeniería. He is currently also with Consejo Nacional de Investigaciones Científicas y Técnicas, Argentina. His research interests include power electronics, electric vehicles, and renewable-energy conversion. 